\title{
Electromagnetic compatibility of multifunctional automation systems for electrical equipment using the example of electric drives
}

\author{
Oleg Kryukov ${ }^{1}$, Alexander Saushev ${ }^{2}$, Olga Shergina ${ }^{3}$, and Artem Butsanets, , $^{4}$ \\ ${ }^{1}$ TSN-Electro LLC (Nizhny Novgorod) \\ ${ }^{2}$ Admiral Makarov State University of Maritime and Inland Shipping \\ ${ }^{3}$ FSFEI of HE "Admiral Makarov State University of Maritime and Inland Shipping" in Kotlas. \\ ${ }^{4}$ Admiral Makarov State University of Maritime and Inland Shipping 5/7, Dvinskaya str, \\ Saint-Petersburg, Russia, 198035
}

\begin{abstract}
The main factors of information compatibility of automatic control systems for energy-saving electric drives are proposed, built on the basis of multifunctional algorithms, when integrated into a single information space of an enterprise. The method for assessing compatibility allows one to purposefully vary the specific shares of data storage and processing processes in the software, as well as to solve the problems of computer modeling and the choice of identification and adaptation algorithms in the general cycle of work. The indicators of the systems operability are given - the coefficients of increasing the productivity of software modules, the essence of the subject area, the accuracy of assessing the input and output information, the probability of achieving the goal, the times of transient processes during information exchange, depending on information resistance, rigidity, memory volume and the level of information-driving logic. It is shown that this will allow avoiding the influence of reactive parameters of information circuits in control systems.
\end{abstract}

\section{Introduction}

In electrical engineering and electric power engineering, the concept of electromagnetic compatibility (EMC) of electrical equipment with a supply network has become generally accepted. EMC in a broad sense is the ability of an electrical device to function normally in its electromagnetic environment without affecting this environment, to which other devices also belong, in an unacceptable way [1-3]. Processes occurring in various parts of the system under consideration should be acceptable for these components both statically and dynamically.

In order to save energy, EMC is understood as the normal functioning of transmitters and receivers of electromagnetic energy in a limited frequency range up to $2000 \mathrm{~Hz}$. In systems providing EMC subsystems, the energy of the transmitters reaches only the desired receivers. These receivers react only to the signals of the transmitters for their intended

* Corresponding author: butsanetsaa@gumrf.ru 
purpose, there are no unwanted mutual influences. Quantitatively, these processes are described by the level and interval of noise, logarithmic relative characteristics, levels of static and dynamic noise immunity of elements. Based on these descriptions, measures for interference suppression are developed [4,5]. In the field of study and design of potent power consumption devices, of paramount importance are such EMC indicators as the effect of receivers on the power factor of the supply network, characterized by the levels of reactive power consumed from the network and distortion power, as well as the resulting overvoltage, voltage fluctuations in the network and other electromagnetic influences and parasitic connections [6-9].

EMC analysis is a prerequisite for the design of modern electrical equipment. This primarily applies to autonomous systems, the visual representatives of which are ship's electric drives and power supply systems.

Let us consider energy saving as the subject of research, which is achieved by ensuring the EMC of electric drives with a load node of the power supply network by means of technical solutions that implement new control algorithms for converters of electric drives. Consequently, the information component of energy-saving electrical equipment systems plays an important role in such complexes $[10,11]$. For its implementation, the necessary and sufficient requirements in terms of electrical engineering must be determined, allowing developers and adjusters to evaluate the effectiveness of automatic (or automated) control systems, the possibility of their improvement and modernization using existing equipment, taking as a basis the algorithms for controlling electrical equipment.

The task of ensuring information compatibility of electric drives with the control center, which embodies an automatic control system (ACS), associated with the operator's console, is urgent. Let us call "information compatibility" the ability of hardware and software of the ACS to function normally with all possible data obtained on the state variables of processes and technological equipment, their parameters, without affecting these processes and equipment in an unacceptable way. At the same time, the authors do not consider the possibility of operation of devices in noise conditions, but take into account only the nature of the computational tasks, which determines the structure of the software, the amount of information processed, the rate of exchange, the need to store data in archives and registers, as well as adapt the software when changing production and technological situations [12$14]$.

In order to compensate of reactive power (CRP) in the load nodes of power supply systems feeding electric drives of enterprises and transport facilities, there are approved technical solutions for controlling the excitation of synchronous motors and converters of any AC drives with reactive power compensation properties [15-18].

The electric drive is included as an essential component in a single process of production, distribution and use of electrical energy. Since the engine does not always operate in the nominal mode with maximum performance, it is possible to use electrical equipment not only for implementation of the technological process, but also for generating reactive power into the network. This possibility has been used for many decades in the operation of synchronous motors (SM), for example, gas pumping units capable of generating capacitive reactive power in the overexcitation mode within the limits determined by the temperature conditions. The SM can be installed with obviously higher power, if the expediency of combining its functions in a given load node of the supply network is proved. Currently, a frequency-controlled asynchronous electric drive with a compensation rectifier (CR) in the DC link of a frequency converter is such a means of reactive power compensation installed directly at the consumer.

The purpose of the work is to develop methodological foundations of information compatibility of automatic control systems for energy-saving electric drives, built on the 
basis of multifunctional algorithms, when integrating them into a single information space of the considered electrical complexes.

\section{Materials and methods}

A short list of control, identification and optimization tasks in energy-saving control of electric drives can be given:

1) control of the excitation currents of SM included in the group of electric drives supplied from a single load node;

2) distribution of the generated reactive power between the stator winding of SM and the compensation rectifier in the exciter circuit;

3) distribution of the installed power of the compensation rectifier in the DC link of a two-link frequency converter of a synchronous or asynchronous AC drive between the process load and the reactive load equal to the compensated reactive power in the distribution network. In this case, calculations of the distortion power, as well as the required voltage value at the $\mathrm{CR}$ output, taking into account the external characteristics of the converter, should be carried out.

Any control systems, no matter what structure they have, are systems for the transmission and processing of information. It is necessary to resolve the issue of measuring all quantities involved in the control process. The developer is characterized by a logical reflection of reality, that is, the ability to penetrate into the essence of $\mathrm{H}$ things and phenomena. It is quite often required to obtain a mathematical expression for the laws of formal logic. For this, in logic, the law of inverse dependence of the volume of the concept $\mathrm{n}$ and its content (essence) $\mathrm{H}$ is distinguished:

$$
\mathrm{H}=\mathrm{M} / \mathrm{n},
$$

where $\mathrm{M}$ is the measured content of the studied or controlled variable, that is, the parameter of the process or object (matter).

Information capacity $\mathrm{n}$, which in formal logic is called the volume of a concept, is numerically equal to the number of information media that are used to form one bit of essence $\mathrm{H}$. The volume of a concept can be measured in programs, functions, elementary operations, in data bits.

On the other hand, it is possible to define the essence $\mathrm{H}$ as the intrinsic content $\mathrm{C}$ of matter in one medium or element of information processing:

$$
\mathrm{C}=\mathrm{M} \cdot \mathrm{H}
$$

Expressing the value of $\mathrm{H}$ from formula (2) and using expression (1), you can get the following relationship: $C=M^{2} / n$ or $n=M^{2} / C$. According to the formula (2), the system's own content is calculated through the essence of its media. In addition, $n=M^{2} / C$ is the logical law of inverse proportionality of the volume of the concept $\mathrm{n}$ and its content $\mathrm{C}$, and information $\mathrm{J}$ is a reflection $\mathrm{M}$, provided it is measured correctly.

Shannon [4] solved the problem of measuring scalar quantities. For discrete information:

$$
\mathrm{H}=-\Sigma_{\mathrm{k}=1, \mathrm{~m}}\left(\mathrm{p}_{\mathrm{k}} \log \left(\mathrm{p}_{\mathrm{k}}\right)\right),
$$

where $p_{k}$ is the probability of a particular state of the studied matter. Since always $H=$ $\Sigma_{\mathrm{k}=1, \mathrm{~m}}\left(\mathrm{p}_{\mathrm{k}}\right)=\int_{-\infty, \infty} \mathrm{f}(\mathrm{x}) \mathrm{dx}=1$, then for uniform distributions with $\mathrm{p}_{\mathrm{k}}=1 / \mathrm{m}=$ const and $\mathrm{f}(\mathrm{x})=$ $1 / x=$ const, the calculation of the information is simplified: $H=\log (m)=\log (x / \Delta x)$.

For example, the essence of the signal about the level of distortion power with variations in the control angles of two groups of valves of the compensation converter in 
the range of 1024 , provided the probability of their state is uniformly distributed, is $\mathrm{H}=$ $\log _{2} 1000=10$ bits.

It is possible to talk about a particular law of probability distribution only having the whole set, that is, having a holistic picture of the subject area. In order for a control or information system to have such a picture, it must have memory and logic that links individual phenomena into a single whole.

With the simultaneous presence of $m$ homogeneous discrete states, sensitive organs that do not have a logical apparatus simply summarize information from the $\mathrm{J}_{\mathrm{D}}$ sensors, in such a way that $J=m J_{D}$. With a continuous arrival of the measured value $x$, when $m=x / \Delta x$, they give information in bits:

$$
\mathrm{J}=\mathrm{x} / \Delta \mathrm{x}
$$

where $\Delta \mathrm{x}$ is the resolution of the sensitive organ.

Relationship (1) allows to measure the primary sensory information of any origin and nature, both continuous and discrete.

To measure discrete information $\mathrm{J}$, it is necessary to take the resolution equal to the "size" of the discrete material medium. For example, information about the voltage $x=220$ $\mathrm{V}$ in the electrical network with an accuracy of $\Delta \mathrm{x}=1 \mathrm{~V}$ is equal to 220 bits, and with an accuracy of $\Delta \mathrm{x}=10 \mathrm{~V}$ it is equal to 22 bits, since an increase in accuracy is accompanied by a proportional increase in information.

In general, control is a response to changes in environmental conditions or system parameters. The process of work of the information subsystem for ensuring control (in the conditions of the unchanged situation) can be reduced to the receipt and analysis of information. The required period of time for the perception of this information (identification) will be called the perception time $\tau$. The average time of information perception will be called the information resistance of the system. It limits the speed of the control system and creates some delay, for which the received information has time to become outdated. In this case, the time $\tau$ is inversely proportional to the throughput of the system, i.e. the maximum speed of information perception that the system is capable of.

In linear systems, information resistance $\tau$ does not depend on the average speed of information receipt: $\mathrm{I}=\Delta \mathrm{J} / \Delta \mathrm{t} \sim \Delta \mathrm{M} / \Delta \mathrm{t}$, where $\mathrm{I}$ is the information current.

In linear information circuits, which can be used to represent control systems using the information method, the probability that the real period $\mathrm{T}$ of information receipt is less than the average information processing time $\tau$ obeys the law $\mathrm{p}=\mathrm{e}^{-\tau \mathrm{ILn} 2}=2^{-\mathrm{I} \tau}$. If we take into account that $\mathrm{H}=\log _{2} \mathrm{~m}$, then we get:

$$
\mathrm{H}=\tau \mathrm{I},
$$

This relationship is similar to Ohm's law for electrical circuits. It is called Ohm's law of information, where the information current is defined as:

$\mathrm{I}=\mathrm{dJ} / \mathrm{dt}=1 / \mathrm{T}_{\mathrm{av}}[\mathrm{bit} / \mathrm{s}]$, where $\mathrm{T}_{\mathrm{av}}$ is the average period of information receipt.

Relation (3) characterizes the performance of the ACS associated with information processing:

$$
\mathrm{I} \cdot \mathrm{H}=\mathrm{H} \cdot(\mathrm{dI} / \mathrm{dt})=\mathrm{dC} / \mathrm{dt}=\mathrm{N},
$$

where $\mathrm{N}$ is the information capacity of the system, $\mathrm{C}$ is the content of the concept.

From (5) taking into account (4) we get:

$$
\mathrm{N}=\mathrm{I}^{2} \tau=\mathrm{H}^{2} / \tau,
$$

Summarizing the above reasoning and conclusions, we can represent the essence $\mathrm{H}$ in the form: 


$$
\mathrm{H}=\mathrm{J} / \mathrm{n}+\mathrm{I} \tau=\mathrm{H}_{\mathrm{n}}+\mathrm{H}_{\tau},
$$

Since the judgments corresponding to expression (6) relate not only to the present, but also to the past, then in such logic there is a historical approach, which is required by the dialectics of the development of processes. At the same time, dialectics also requires consideration of the phenomenon in its possible further development in the future. The limiting rate $1 / \tau$, where $\tau$ is the average time of processing a unit of information, can be achieved in the general case as the control program adapts to the processes taking place in the control object. In this case, the rate of information processing will constantly increase from 0 to $1 / \tau$.

Let the adaptation of the program take place at a constant rate and take time $\Delta t$. Then the limiting acceleration of the data recognition rate for the considered part of the program will be: $1 / \tau \cdot \Delta \tau=1 / t^{2}$ acceleration, and the inverse value of this limiting acceleration is called the rigidity (inductance) $\mathrm{L}$, which has the dimension of the square of time.

Taking into account the expression $H=\log (m)=\log (x / \Delta x)$, we get:

$$
\mathrm{H}_{\mathrm{L}}=\mathrm{L} \cdot(\mathrm{dI} / \mathrm{dt}) \text {. }
$$

But the combination of expressions (6) and (7) states not only intentions, but also movement towards the goal, taking into account the prehistory:

$$
\mathrm{H}=\mathrm{H}_{\mathrm{n}}+\mathrm{H}_{\tau},+\mathrm{H}_{\mathrm{L}}=\mathrm{J} / \mathrm{n}+\mathrm{I} \tau+\mathrm{L} \cdot(\mathrm{dI} / \mathrm{dt})=(1 / \mathrm{n}) \cdot \int \mathrm{I} \cdot \mathrm{dt}+\mathrm{I} \tau+\mathrm{L} \cdot(\mathrm{dI} / \mathrm{dt}) .
$$

The object of control can only be systems that have more than one state, and one (or several) of these states, corresponding to the optimum of the control system's existence, acts as the goal of control. The goal can be achieved with a probability $\mathrm{p}_{\mathrm{gk}}<1$, so that the state corresponding to the desired goal of the system, even due to control, has some uncertainty, estimated by the entropy (essence): $\mathrm{H}_{\mathrm{goal}}=-\Sigma_{\mathrm{k}} \mathrm{p}_{\mathrm{gk}} \log \left(\mathrm{p}_{\mathrm{gk}}\right)$.

If before control the system was characterized by the essence: $\Sigma_{\mathrm{k}} \mathrm{p}_{0 \mathrm{k}} \log \left(\mathrm{p}_{0 \mathrm{k})}\right.$, where $\mathrm{p}_{0 \mathrm{k}}$ is the probability of the system states (before control), then the essence of control is: $\Delta \mathrm{H}=\mathrm{H}_{0}$ $-\mathrm{H}_{\text {goal }}$.

The essence $\mathrm{H}$ of the system is the functional of its existence, which is subject to optimization in the control process. The goal and meaning of any control is to change in one direction or another this priori probability of an event to some new value $p_{\text {con, where }}$ $\mathrm{p}_{\mathrm{con}}$ is the probability of an event under the condition that this event is controlled. The new value of the information potential corresponds to the value of $\mathrm{p}_{\text {con }}: \mathrm{H}_{\mathrm{con}}=-\log \left(\mathrm{p}_{\mathrm{con}}\right)$. Thus, the essence of the control carried out by the information source can be characterized by some information voltage: $\Delta \mathrm{H}=\mathrm{H}_{0}-\mathrm{H}_{\text {con }}=\log \left(\mathrm{p}_{\mathrm{con}} / \mathrm{p}_{0}\right)$. From this ratio, we can conclude that the information voltage (essence) of the source $\Delta \mathrm{H}$ can be either greater than zero, when its goal is to increase the probability of an event, and less than zero, when its goal is to reduce the probability of an event.

The efficiency of the source depends on how quickly it provides control information when the state of the load changes. The delay present in the source devalues the control information issued by it and performs the functions of the internal information resistance of the source. The voltage of the information source that it has at idle, without information load (without taking into account the internal resistance - delay in the source), can be called information driving logic (IDL) and denoted by $\mathrm{h}$. With an information load, the information current I creates a drop in the information voltage $I \tau_{\mathrm{V}}$, which reduces $\mathrm{h}$ to the working information voltage:

$\Delta \mathrm{H}=\mathrm{h}-\mathrm{I} \tau_{\mathrm{V}}$.

It is possible to increase the voltage of the source, or reduce its internal resistance to the desired value, since Kirchhoff's information laws are applicable to such circuits. 
Real information circuits are often complex combinations of information sources and receivers, not limited to serial or parallel connections. In the general case, applying Kirchhoff's information laws, it is possible to compose equations for nodes and circuits, the solutions of which allow finding information voltages and currents, including in transient modes.

For example, consider an information circuit for filling a memory with a capacity $n$ from an information source with a voltage $\Delta H$ through a resistance $\tau$ ( $\tau$ is the filling time of one memory cell). In continuous systems, $\tau$ is the time to fill the minimum discernible portion of memory. The source voltage is balanced:

$$
\Delta \mathrm{H}=\tau \mathrm{I}+\Delta \mathrm{H}_{\mathrm{n}}^{\prime},
$$

where $\Delta \mathrm{H}_{\mathrm{n}}^{\prime}$ is the information voltage in memory.

During the memory filling time, the current will change, therefore $\Delta \mathrm{H}_{\mathrm{n}}^{\prime}=\int \mathrm{Idt}$.

The solution to these equations: $I=(\Delta H / \tau) \mathrm{e}^{-(\mathrm{t} / \mathrm{n} \tau)}$. We denote $\mathrm{T}=\mathrm{n} \tau$ and call it the memory filling time constant. It is generally accepted that the memory is filled practically at $\mathrm{t}=(3-5) \mathrm{T}$. In ACS, the current is regulated and constant during the process of filling the memory, for example, when transmitting information through communication channels. In this case, we get:

$$
\Delta \mathrm{H}=\mathrm{I} \cdot(\tau+\mathrm{T} / \mathrm{n})
$$

Relation (8) makes it possible to determine the memory filling current I at a given filling time $\mathrm{t}=5 \mathrm{~T}$ and at a given probability of a certain state of the memory after filling: $\Delta \mathrm{H}=-\log _{2}\left(1 / \mathrm{p}_{\mathrm{g}}\right)$. Passing to the Laplace images, we obtain the transfer function of the memory filling circuit: $\mathrm{I}(\mathrm{s}) / \Delta \mathrm{H}(\mathrm{s})=\mathrm{ns} /(\mathrm{Ts}+1)$.

The property of rigidity is explained by the inability of the program segment to immediately change the algorithm of its work. However, outwardly, these properties are manifested in active opposition to control, i.e. in the development of a counter information tension that counteracts control. Transient processes in information circuits of this nature will be described by the corresponding differential equations.

\section{Results}

In practice, it is possible to detect manifestations of rigidity caused by external influences, when the behavior is not determined by its own properties, applied by the algorithm. This mutual influence of information circuits is called mutual rigidity. The influence of mutual rigidity can manifest itself not only in the coordination of algorithms for the operation of various circuits, but also in the opposite way, when one of the loads controls an algorithm that is different from the algorithms for the operation of loads in other similar circuits.

From the analogy of information and electrical circuits, it follows that capacitive (with memory) and rigid information modules of software can have a noticeable effect on the properties of the systems under consideration, since at short time intervals they behave like voltage and current sources. The operation of any control program can be considered as a cyclically repeating sequence of various structural states and modes. At the same time, sources of the same type cannot be connected with each other directly in this time sequence, but only with different types, or by means of additional inclusion of information resistance with a series connection of concepts (capacities) or with a parallel connection of rigidity (inductances).

In an energy-saving electric drive, where a multifunctional control system cannot be reduced to a set of loops with subordinate regulation due to the presence of connected control programs, identification and optimization, tree-like hierarchical control and 
information collection circuits are used. However, any control system is accompanied by the organization of feedback, with which it always forms a closed loop. Consider the structure of an electric drive control system, which consists of three levels with branches at each level. This system works with a system for collecting and processing information similar in structure, forming a closed loop of control and monitoring with it. Such a structure corresponds to the upper control levels of the energy-saving cluster of electric drives. In it, the main program for calculating the values of the capacitive reactive power generated into the network and the required total active power required for the technological process with the IDL level equal to $\mathrm{h}$ has two direct control modules $\mathrm{K}_{\mathrm{I}}$ and $\mathrm{K}_{\mathrm{II}}$. Each of these modules controls the operation of two subroutines $\mathrm{K}_{1}$ and $\mathrm{K}_{2}$ and, respectively, subroutines $\mathrm{K}_{3}$ and $\mathrm{K}_{4}$. In addition, the main program has two measurement and identification modules $\mathrm{K}_{\mathrm{III}}$ and $\mathrm{K}_{\mathrm{IV}}$, whose functions include monitoring and evaluating the results of the work of subroutines $\mathrm{K}_{1}$ and $\mathrm{K}_{2}$, as well as $\mathrm{K}_{3}$ and $\mathrm{K}_{4}$.

Symbols K define the transfer functions of the corresponding modules and subroutines when analyzing the structure in a transient mode (when switching to a new set of data on external influences on electric drives) or their information power amplification factors in the established operating mode.

The voltages and currents of all levels of the structure in an open-loop system are usually easy to set. Let $\mathrm{J}$ be the number of emerging control situations that the main program manages to resolve during the entire working time $T$, its direct control modules $\mathrm{J}_{\mathrm{I}}, \mathrm{J}_{\mathrm{II}}$, subroutines $-\mathrm{J}_{1}, \mathrm{~J}_{2}, \mathrm{~J}_{3}, \mathrm{~J}_{4}$, measurement and identification modules $-\mathrm{J}_{\mathrm{III}}, \mathrm{J}_{\mathrm{IV}}$. Their average information currents are respectively:

$$
\begin{gathered}
\mathrm{I}_{\mathrm{I}}+\mathrm{I}_{\mathrm{II}}=\mathrm{J} / \mathrm{T} ; \mathrm{I}_{1}+\mathrm{I}_{2}=\mathrm{J}_{1} / \mathrm{T} ; \mathrm{I}_{3}+\mathrm{I}_{4}=\mathrm{J}_{\mathrm{II}} / \mathrm{T} ; \\
\mathrm{I}_{\mathrm{III}}=\mathrm{J}_{\mathrm{III}} / \mathrm{T} ; \mathrm{I}_{\mathrm{IV}}=\mathrm{J}_{\mathrm{IV}} / \mathrm{T} .
\end{gathered}
$$

Feedback information currents:

$$
\mathrm{I}_{1}{ }^{\prime}=\mathrm{J}_{1} / \mathrm{T} ; \mathrm{I}_{2}{ }^{\prime}=\mathrm{J}_{2} / \mathrm{T} ; \mathrm{I}_{3}{ }^{\prime}=\mathrm{J}_{3} / \mathrm{T} ; \mathrm{I}_{4}{ }^{\prime}=\mathrm{J}_{4} / \mathrm{T} .
$$

Moreover, each part of the software would have to spend time, respectively, to resolve each situation: $\tau, \tau_{\mathrm{I}}, \tau_{\mathrm{II}}, \tau_{\mathrm{III}}, \tau_{\mathrm{IV}}, \tau_{1}, \tau_{2}, \tau_{3}, \tau_{4}$.

Then you can calculate their essence for a steady state of operation:

$$
\begin{gathered}
\mathrm{h}=\left(\mathrm{I}_{\mathrm{I}}+\mathrm{I}_{\mathrm{II}}\right) \tau ; \mathrm{H}_{\mathrm{I}}=\left(\mathrm{I}_{1}+\mathrm{I}_{2}\right) \tau_{\mathrm{I}} ; \mathrm{H}_{\mathrm{II}}=\left(\mathrm{I}_{3}+\mathrm{I}_{4}\right) \tau_{\mathrm{II}} ; \\
\mathrm{H}_{1}=\mathrm{I}_{1} \tau_{1} ; \mathrm{H}_{2}=\mathrm{I}_{2} \tau_{2} ; \mathrm{H}_{3}=\mathrm{I}_{3} \tau_{3} ; \mathrm{H}_{4}=\mathrm{I}_{4} \tau_{4} ; \\
\mathrm{H}_{\mathrm{III}}=\mathrm{I}_{\mathrm{III}} \tau_{\mathrm{III}} ; \mathrm{H}_{\mathrm{IV}}=\mathrm{I}_{\mathrm{IV}} \tau_{\mathrm{IV}} ; \mathrm{H}_{1}=\mathrm{H}_{2} ; \mathrm{H}_{3}=\mathrm{H}_{4} .
\end{gathered}
$$

The obtained ratios allow us to determine the performance of all levels $\mathrm{N}=\mathrm{I} \cdot \mathrm{H}$ and the amplification factors of this performance:

$$
\begin{array}{cl}
\mathrm{K}_{\mathrm{I}}=\mathrm{H}_{\mathrm{I}}\left(\mathrm{I}_{1}+\mathrm{I}_{2}\right) / \mathrm{hI}_{\mathrm{I}} ; & \mathrm{K}_{\mathrm{II}}=\mathrm{H}_{\mathrm{II}}\left(\mathrm{I}_{3}+\mathrm{I}_{4}\right) / \mathrm{hI}_{\mathrm{II}} ; \\
\mathrm{K}_{1}=\mathrm{H}_{1} \mathrm{I}_{1}{ }^{\prime} / \mathrm{H}_{\mathrm{I}} \mathrm{I}_{1} ; \quad \mathrm{K}_{2}=\mathrm{H}_{2} \mathrm{I}_{2}{ }^{\prime} / \mathrm{H}_{\mathrm{I}} \mathrm{I}_{2} ; \mathrm{K}_{3}=\mathrm{H}_{3} \mathrm{I}_{3}{ }^{\prime} / \mathrm{H}_{\mathrm{II}} \mathrm{I}_{3} ; \quad \mathrm{K}_{4}=\mathrm{H}_{4} \mathrm{I}_{4}{ }^{\prime} / \mathrm{H}_{\mathrm{II}} \mathrm{I}_{4} ; \\
\mathrm{K}_{\mathrm{III}}=\mathrm{H}_{\mathrm{III}} \mathrm{I}_{\mathrm{III}} / \mathrm{H}_{1}\left(\mathrm{I}_{1}+\mathrm{I}_{2}\right) ; \mathrm{K}_{\mathrm{IV}}=\mathrm{H}_{\mathrm{IV}} \mathrm{I}_{\mathrm{IV}} / \mathrm{H}_{3}\left(\mathrm{I}_{3}+\mathrm{I}_{4}\right) .
\end{array}
$$

Similarly, if the memory capacities and rigidity of all links are known, the corresponding transfer functions of the links can be determined, which, in turn, will allow finding the transfer function of the entire closed-loop system. In the implemented structure, $\mathrm{K}_{1}$ and $\mathrm{K}_{2}$ are connected in parallel with each other and in series with $\mathrm{K}_{\mathrm{I}}$, that is, their equivalent transfer function has the form: $\mathrm{K}_{\mathrm{I}}\left(\mathrm{K}_{1}+\mathrm{K}_{2}\right) . \mathrm{K}_{\mathrm{II}}, \mathrm{K}_{3}$ and $\mathrm{K}_{4}$ are connected in the same way, so their transfer function is determined by the expression: $\mathrm{K}_{\mathrm{II}}\left(\mathrm{K}_{1}+\mathrm{K}_{2}\right)$. In turn, 
each of these circuits is covered by feedback with the coefficient $\mathrm{K}_{\mathrm{III}}$ and $\mathrm{K}_{\mathrm{IV}}$, respectively, that is, they have equivalent transfer functions:

$$
\mathrm{K}_{\mathrm{I}}\left(\mathrm{K}_{1}+\mathrm{K}_{2}\right) /\left(1+\mathrm{K}_{\mathrm{I}}\left(\mathrm{K}_{1}+\mathrm{K}_{2}\right) \mathrm{K}_{\mathrm{III}} \text { and } \mathrm{K}_{\mathrm{II}}\left(\mathrm{K}_{3}+\mathrm{K}_{4}\right) /\left(1+\mathrm{K}_{\mathrm{II}}\left(\mathrm{K}_{3}+\mathrm{K}_{4}\right) \mathrm{K}_{\mathrm{IV}}\right. \text {. }\right.
$$

Since both considered closed loops are parallel to each other, the transfer function of the circuit, which is the ratio of the total intellectual power of all program elements $N_{\Sigma}$ to the power of the IDL of the main program, will be determined by the expression:

$$
\mathrm{N}_{\Sigma} / \mathrm{N}_{\mathrm{h}}=\mathrm{K}_{\mathrm{I}}\left(\mathrm{K}_{1}+\mathrm{K}_{2}\right) /\left(1+\mathrm{K}_{\mathrm{I}}\left(\mathrm{K}_{1}+\mathrm{K}_{2}\right) \mathrm{K}_{\mathrm{III}}+\mathrm{K}_{\mathrm{II}}\left(\mathrm{K}_{3}+\mathrm{K}_{4}\right) /\left(1+\mathrm{K}_{\mathrm{II}}\left(\mathrm{K}_{3}+\mathrm{K}_{4}\right) \mathrm{K}_{\mathrm{IV}}\right. \text {. }\right.
$$

\section{Discussion}

The information component of energy-saving electrical equipment systems and, first of all, automated electric drives, plays an important role in the control of the complexes under consideration. For its implementation, the necessary and sufficient requirements in terms of electrical engineering must be determined, allowing developers and adjusters to evaluate the effectiveness of automatic (or automated) control systems, the possibility of their improvement and modernization using the existing equipment, taking as a basis the algorithms for controlling electric drives.

The purpose and meaning of any control is to change in one direction or another a priori probability of an event to some new value. Thus, the essence of the control carried out by the information source can be characterized by the information voltage of the informationdriving logic, which is a logical rather than an energy characteristic of the control process.

The given performance indicators of systems, such as the performance amplification factors of software modules, the essence of the subject area, the accuracy of evaluating input and output information, the probability of achieving the goal, the time of transient processes during information exchange, depending on information resistance, rigidity, memory volume and the level of information-driving logic, are objective factors in assessing the functional efficiency of information systems.

In this case, control is reduced to switching program instructions, which must be connected according to the rules of "potential sources" and "current sources", which for a short period of time in this logic are, respectively, the concepts (capacity) and rigidity (inductance). Sources of the same type cannot be connected with each other directly, but only with sources of different types. They can also be connected by means of additional inclusion of information resistance in series connection of concepts (capacities) or in parallel connection of rigidity (inductances).

\section{Conclusion}

When synthesizing microprocessor-based control systems for electric drives with limited speed, it is advisable, if possible, to simulate the control process in advance in the entire range of variable changes and present the resulting decision tables as arrays for selecting control data from a set of input signals. This will allow avoiding the influence of "reactive" parameters of information circuits in control systems of electric drives.

\section{References}

1. V.R. Milov, B.A. Suslov, O.V. Kryukov, Automation and Remote Control 72(5), 1095-1101 (2011) DOI 10.1134/S0005117911050183 
2. O.V. Kryukov, A.V. Serebryakov, Bulletin of South Ural State University. Series: Power Engineering 17(3), 102-110 (2017) DOI: 10.14529/power170312

3. O.V. Kryukov, Bulletin of South Ural State University. Series: Power Engineering 17(1), 56-62 (2017) DOI 10.14529/power170108

4. S.N. Kadin, A.P. Kazachenko, O.V. Kryukov, A.V. Reunov, Measurement Techniques 54(8), 944-952 (2011) DOI 10.1007/s11018-011-9832-7

5. O.V. Kryukov, Automation and Remote Control 74(6), 1043-1048 (2013) DOI 10.1134/S0005117913060143

6. S.A. Babichev, P.A. Zakharov, O.V. Kryukov, Automation and Remote Control 72(6), 175-180 (2011) DOI 10.1134/S0005117911010176

7. S.A. Babichev, O.V. Kryukov, V.G. Titov, Russian Electrical Engineering 81(12), 649655 (2010) DOI 10.3103/S1068371210120047

8. S.A. Babichev, E.V. Bychkov, O.V. Kryukov, Russian Electrical Engineering 81, 489494 (2010) DOI 10.3103/S1068371210090075

9. N.V. Kiyanov, O.V. Kryukov, D.N. Pribytkov, A.V. Gorbatushkov, Russian Electrical Engineering 78(11), 621-627 (2007) DOI 10.3103/S1068371207110120

10. O.V. Kryukov, A.V. Serebryakov, Russian Electrical Engineering 86(4), 208-212 (2015) DOI 10.3103/S1068371215040069

11. I.P. Kopylov, Yu.P. Sonin, I.V. Gulyaev, V.V. Nikulin, Russian Electrical Engineering 70(9), 35-41 (1999) DOI 10.3103/S1068371216120038

12. O.V. Kryukov, A.V. Serebryakov, 2nd International Conference on Industrial Engineering, Applications and Manufacturing, ICIEAM 2016 - Proceedings 2, 7911445 (2016) DOI: 10.1109/ICIEAM.2016.7911445

13. O.V. Kryukov, A.V. Serebryakov, Bulletin of South Ural State University. Series: Power Engineering 16(1), 66-74 (2016) DOI 10.14529/power160110

14. O.V. Kryukov, Russian Electrical Engineering 83, 516-520 (2012) DOI 10.3103/S1068371212090064

15. O.V. Kryukov, I.V. Gulyaev, D.Y. Teplukhov, Russian Electrical Engineering 90(7), 473-478 (2019) DOI 10.3103/S1068371219070083

16. A.S. Belousov, V.N. Meshcheryakov, S. Valtchev, O.V. Kryukov, Proceedings - 2019 1st International Conference on Control Systems, Mathematical Modelling, Automation and Energy Efficiency, SUMMA 2019, 444-449 (2019) DOI 10.1109/SUMMA48161.2019.8947487

17. V.F. Samoseiko, A.V. Saushev, N.V. Belousova, Proceedings - 2019 International Ural Conference on Electrical Power Engineering, UralCon 2019, 284-289 (2019) DOI.10.1109/URALCON.2019.8877625

18. O.V. Kryukov, D.A. Blagodarov, N.N. Dulnev, et al., 10th International Conference on Electrical Power Drive Systems, ICEPDS 2018 - Conference Proceedings 10, 8571670 (2018) DOI: 10.1109/ICEPDS.2018.8571670 